\title{
Isotopic and molecular distributions of biochemicals from fresh and buried Rhizophora mangle leaves $\dagger$
}

\author{
Barbara J. Smallwood, ${ }^{a}{ }^{a}$ Matthew J. Wooller, ${ }^{b}$ Myrna E. Jacobson ${ }^{c}$ and \\ Marilyn L. Fogel ${ }^{d}$ \\ ${ }^{a}$ The SCOOBy Lab, Department of Oceanography, Texas A+M University, College \\ Station, TX 77843-3146, USA. E-mail: bsmall@ocean.tamu.edu \\ ${ }^{b}$ Alaska Stable Isotope Facility: Water and Environmental Research Center/School of \\ Fisheries and Ocean Sciences, Duckering Building, University of Alaska, Fairbanks, AK, \\ 99775-5860, USA \\ ${ }^{c}$ University of Southern California, 3616 Trousdale Parkway, Los Angeles, CA, 90089- \\ 0371, USA \\ ${ }^{d}$ Geophysical Laboratory, Carnegie Institution of Washington, 5251 Broad Branch Road \\ NW, Washington DC, 20015-1305, USA
}

Received 29th July 2003, Accepted 24th November 2003

Published as an Advance Article on the web 5th December 2003

\begin{abstract}
Rhizophora mangle L. (red mangrove) is the dominant species of mangrove in the Americas. At Twin Cays, Belize (BZ) red mangroves are present in a variety of stand structures (tall $>5 \mathrm{~m}$ in height, transition $\sim 2-4 \mathrm{~m}$ and dwarf $\sim 1-1.5 \mathrm{~m}$ ). These height differences are coupled with very different stable carbon and nitrogen isotopic values ${ }^{1}$ (mean tall $\delta^{13} \mathrm{C}=-28.3 \%$, $\delta^{15} \mathrm{~N}=0 \%$; mean tall $\delta^{13} \mathrm{C}=-25.3 \%$, $\delta^{15} \mathrm{~N}=-10 \%$ ). To determine the utility of using these distinct isotopic compositions as 'biomarkers' for paleoenvironmental reconstruction of mangrove ecosystems and nutrient availability, we investigated the distribution and isotopic $\left(\delta^{13} \mathrm{C}\right.$ and $\left.\delta^{15} \mathrm{~N}\right)$ composition of different biochemical fractions (water soluble compounds, free lipids, acid hydrolysable compounds, individual amino acids, and the residual un-extractable compounds) in fresh and preserved red mangrove leaves from dwarf and tall trees. The distribution of biochemicals are similar in dwarf and tall red mangrove leaves, suggesting that, regardless of stand structure, red mangroves use nutrients for biosynthesis and metabolism in a similar manner. However, the $\delta^{13} \mathrm{C}$ and $\delta^{15} \mathrm{~N}$ of the bulk leaf, the biochemical fractions, and seven amino acids can be used to distinguish dwarf and tall trees at Twin Cays, BZ. The data support the theory that the fractionation of carbon and nitrogen occurs prior to or during uptake in dwarf and tall red mangrove trees. Stable carbon and nitrogen isotopes could, therefore, be powerful tools for predicting levels of nutrient limitation at Twin Cays. The $\delta^{13} \mathrm{C}$ and $\delta^{15} \mathrm{~N}$ of biochemical fractions within preserved leaves, reflect sedimentary cycling and nitrogen immobilization. The $\delta^{15} \mathrm{~N}$ of the immobilized fraction reveals the overlying stand structure at the time of leaf deposition. The isotopic composition of preserved mangrove leaves could yield significant information about changes in ecosystem dynamics, nutrient limitation and past stand structure in mangrove paleoecosystems.
\end{abstract}

\section{Introduction}

The mangrove environment that dominates the world's tropical and subtropical coasts is currently threatened by clear cutting and nitrification. ${ }^{1,2}$ Mangroves shield coasts from natural episodic events such as hurricanes; serve as nurseries for juvenile fish ${ }^{3}$ are an important source of nutrients for offshore biological production; and are essential for keeping coastal waters free of sediment, which subsequently helps preserve coral reefs

Rhizophora mangle L., the red mangrove, is one of the major species of mangrove in the Americas. ${ }^{2}$ It has a broad range of stand structures $\left(<1 \mathrm{~m}\right.$ to $>60 \mathrm{~m}$ ) for trees of the same age. ${ }^{3,4}$ These differences in height are due to variations in the balance and concentration of available nutrients (e.g., nitrogen vs. phosphorous $v s$. potassium), which can fluctuate over very small distances (i.e., meters). ${ }^{3,5-7}$ The red mangrove's adaptability to nutrient alterations and dynamic water levels has

$\dagger$ Presented at the ACS Division of Geochemistry Symposium 'Stable isotope signatures for establishing paleoenvironmental change', Orlando, April 2002. ensured survival of this species through sea-level change and anthropogenic nutrient release.

Twin Cays $\left(16^{\circ} 50^{\prime} \mathrm{N}, 88^{\circ} 06^{\prime} \mathrm{W}\right)$, a peat-based, 92 ha archipelago of offshore $(12 \mathrm{~km})$ mangrove islands, is located inside the crest of the barrier reef of central Belize (BZ). The terrigenous input of organic matter is restricted to dust deposited by wind and rain. The shoreline gradient is intertidal and is interrupted by tidal creeks, open flats, and shallow interior ponds. The vegetation is dominated by the red mangrove with two other species, Avicennia germinans (L.) Stearn. (black mangrove) and Laguncularia racemosa (L.) Gaertn. f. (white mangrove), present in lower abundance. Mangrove forests at Twin Cays are characterized by a treeheight gradient that parallels other gradients, such as productivity and tidal flushing. ${ }^{3,6-8}$ The tree-height gradient at the site can be subdivided into three zones: (1) A fringe of uniformly tall $(5-6 \mathrm{~m})$ red mangrove trees that dominate the seaward-most zone of the islands. (2) A transition zone (2-4 m in height), where all three mangrove species are present. (3) A zone of uniformly stunted (dwarf; $\sim 1-1.5 \mathrm{~m}$ ) red mangrove trees, with stands in the interior of the islands. ${ }^{3}$

Fertilization experiments at Twin Cays have shown that trees 
in the fringe zone are nitrogen limited; dwarf trees are phosphorous limited; and trees in the transition zone are limited by both nitrogen and phosphorous. ${ }^{3}$ Previous studies at Twin Cays have described the bulk carbon and nitrogen isotopic composition of red mangrove leaves from experimental plots that traverse all three zones of nutrient limitation. ${ }^{7}$ A wide range of carbon and nitrogen isotope values has been described for red mangrove, with dwarf trees having the highest carbon (mean $\delta^{13} \mathrm{C}=-25.3 \%$ ) and lowest nitrogen isotopic composition (mean $\delta^{15} \mathrm{~N}=-10 \%$ ), compared with tall trees of the same species (mean $\delta^{13} \mathrm{C}=-28.3 \%$ and mean $\delta^{15} \mathrm{~N}=0.0 \%{ }^{1}$ ). This contrasts to relatively uniform carbon and nitrogen isotopic compositions of the peat matrix throughout the differing nutrient gradients at Twin Cays, previously reported. ${ }^{9,10}$

These isotopic distinctions within the same species of red mangrove may permit inference about past stand structure if (1) it is established which chemical fractions hold the isotopic signal and (2) despite diagenesis, this isotopic signal is retained by the preserved leaves. This paper addresses both of these requirements by measuring the carbon and nitrogen isotopic composition of a variety of biochemical fractions (water soluble compounds, free lipids, acid hydrolysable compounds, individual amino acids and the insoluble residual compounds) in fresh and preserved red mangrove leaves sampled at Twin Cays, BZ. Although previous work has shown that amino acids are labile, ${ }^{11}$ they are thought to degrade relatively slowly after burial. ${ }^{12-15}$ Recent research has highlighted the immobilization of nitrogen by tannins in mangrove ecosystems; ${ }^{16}$ nitrogen from amino acids is believed to be incorporated into complex, recalcitrant pools of organic matter and preserved in peat sediments. These factors provided a focus for the research presented in this paper.

Fresh leaves were sampled from red mangrove trees growing in areas of apparent phosphorous limitation and flooding (dwarf trees) and in areas of nitrogen limitation (tall trees). Preserved leaves were analyzed from two peat cores $(\sim 50 \mathrm{~cm}$ long) under two mangrove stands at Twin Cays, one from under a dwarf stand and one from under a tall stand. Wooller et al. ${ }^{10}$ provided information on the taphonomy of dwarf and tall trees in terms of their bulk isotopic characteristics, and this paper is essentially a continuation of that study.

\section{Methods}

\section{Field collection of samples from Belize}

A fully expanded canopy leaf was taken from three tall and three dwarf Red mangrove trees during October and November 2000 from Twin Cays, BZ. Leaf samples were dried at $50{ }^{\circ} \mathrm{C}$ under $\mathrm{N}_{2}$ at the Smithsonian Marine Station, Carrie Bow Cay, BZ. Samples were then packaged and transported to the Geophysical Laboratory, Carnegie Institution of Washington for stable isotope analyses.

\section{Leaf samples from mangrove peat}

A sediment core was taken to a depth of $50 \mathrm{~cm}$ from peat underlying both a dwarf and a tall red mangrove stand. The two sediment cores were sectioned into one $\mathrm{cm}$ intervals, placed into Petri dishes and kept at $4{ }^{\circ} \mathrm{C}$. Sections of the sediment core were sampled for the remains of red mangrove leaves. Leaf remains were located at $\sim 30 \mathrm{~cm}$ in both cores and picked from the surrounding peat. The leaf remains were frozen and freeze dried in a manner similar to the fresh leaf samples and analyzed as reported below. Preserved leaf remains from under the modern dwarf and tall red mangrove stands will be described as 'PL dwarf' and 'PL tall', respectively.

\section{Leaf extraction}

The freeze-dried fresh red mangrove leaves from three dwarf trees and three tall trees and the preserved leaves from the peat cores, were sequentially extracted for free lipids and bound amino acids. Free lipids were extracted by sonication $(3 \times 5 \mathrm{~min})$ of the dry leaf $(20 \mathrm{mg})$ with dichloromethane and methanol $(9: 1,10 \mathrm{ml})$ and separated from the residual leaf via centrifugation. Bound amino acids were extracted from the remaining leaf material, by hydrolysis $(1 \mathrm{ml}, 6 \mathrm{~N} \mathrm{HCl}$ constant boiling, Pierce Chemicals, $110{ }^{\circ} \mathrm{C}, 20 \mathrm{~h}$ ), as previously described. ${ }^{17,18}$ Sugars, carbohydrates and free amino acids were extracted from a separate portion of the same leaf, by sonication with water (ultra pure, $3 \times 10 \mathrm{ml} \times 5 \mathrm{~min}$ ). The water extracts were separated by centrifugation from the residual leaf and freeze-dried for isotopic analysis. The bulk lipid extract, the water soluble extract, the bound amino acid extract, and a portion of residual leaf at each stage of extraction were analyzed for total percent organic carbon (TOC), total percent nitrogen (TN) and stable carbon and nitrogen isotopic composition, as described below.

\section{Bulk carbon and nitrogen stable isotope analyses}

An aliquot ( $\sim 700$ to $800 \mu \mathrm{g}$ ) of each extract was weighed into a tin capsule, which was sealed and introduced via the EA carouse $^{19}$ into the autosampler (A2100) of a CE Instruments, NA 2500 series elemental analyzer (EA). Isotope ratios of the combustion gases were analyzed using continuous-flow, stable isotope ratio mass spectrometry (Finnigan MAT, Delta $^{\text {plus }} \mathrm{XL}^{10,17}$ ).

\section{Carbon and nitrogen stable isotope analyses of individual amino acids and free lipids}

The bound amino acids (extracted from mangrove leaves) were derivatized with 2-propanol and trifluoracetic anhydride (N-TFA) to form N-TFA amino acid isopropyl esters, similar to previously reported methods. ${ }^{17,18,20}$ The carbon and nitrogen isotopic composition of each derivatized amino acid was determined by isotope ratio monitoring gas chromatography mass spectrometry (irmGC-MS). irmGC-MS analyses were performed using a Varian gas chromatograph coupled to a Finnigan MAT, Delta ${ }^{\text {plus }}$ XL via a combustion interface. The carbon isotopic composition of the individual compounds was measured relative to gaseous $\mathrm{CO}_{2}$ or $\mathrm{N}_{2}$ standards that were introduced as a series of pulses, directly into the ion source at times that did not coincide with the sample peaks. Amino acids were separated via a $50 \mathrm{~m}$ HP Ultra-1 analytical GC column that operated under a set temperature program (held at $75^{\circ} \mathrm{C}$ for $2 \mathrm{~min}$, ramped to $90{ }^{\circ} \mathrm{C}$ at $4{ }^{\circ} \mathrm{C}$ per min, held for $4 \mathrm{~min}$, ramped to $280{ }^{\circ} \mathrm{C}$ at $30{ }^{\circ} \mathrm{C}$ per min and held for $15 \mathrm{~min}$, the injector temperature was $220{ }^{\circ} \mathrm{C}$ ). The derivatization agents add carbon by way of the addition of isopropyl and $\mathrm{N}$-trifluoroacetyl groups to the amino acid. It was therefore, necessary to calculate $\delta^{13} \mathrm{C}$ values against known standards that were derivatized and extracted along with each batch of samples. The equation used to determine the final $\delta^{13} \mathrm{C}$ value for each amino acid was as follows:

$\delta^{13} \mathrm{Caa}_{\text {sample }}=\frac{\left(\delta^{13} \mathrm{Caa}_{\mathrm{dsa}}-\delta^{13} \mathrm{Caa}_{\mathrm{dst}}+\delta^{13} \mathrm{Caa}_{\text {standard }} P_{\text {std }}\right)}{P_{\text {std }}}$

where dsa and dst refer to the derivatized sample and amino acid standard, respectively, and $P_{\text {std }}$ is equal to the proportion of carbon in the derivative from the amino acid. Each sample was run a total of three times and each group (dwarf or tall) had three fresh leaves, making nine runs per group of dwarf or tall trees. The maximum standard deviation for amino acids from plant leaves was determined to be $\pm 0.86 \%$. Reproducibility for the $\delta^{13} \mathrm{C}$ of amino acid standard mixtures was $\pm 0.59 \%$. Glycine (gly) co-eluted with an unknown 
compound and was not used in this study. Derivitization did not disrupt the nitrogen molecules of the amino acids, so nitrogen isotopes were determined directly from the Finnigan Isodat software. Standards were analyzed once and only one of each of the dwarf and tall fresh and preserved leaves were analyzed (four in total).

\section{Results}

\section{Distribution of chemical groups in red mangrove leaves}

Fresh leaves. The proportions of individual compound classes of the dwarf and tall fresh leaves are shown in Tables 1 and 2. The major compounds in the leaf consist of the unextractable structural cellulose, hemi-cellulose, phenols, tannins and lignin. The un-extractable fraction is similar in dwarf and tall leaves, $($ mean $=72.81 \pm 7.16 \%$ for dwarf leaves, $n=3$; mean $=68.41 \pm 5.57 \%$ for tall leaves, $n=3$; Tables 1 and 2). Moreover, the relative percentages of all biochemical fractions, relative to carbon, are statistically similar in leaves from both dwarf and tall trees $\left(T<T_{\text {crit }}\right.$ at $\left.\alpha=0.05\right)$. Total organic carbon (TOC), total nitrogen $(\mathrm{TN})$ and $\mathrm{C} / \mathrm{N}$ (Tables 1 and 2) are similar, with little distinction apparent between the two leaf categories. The composition of major biochemical fractions in fresh dwarf and tall leaves are statistically similar; however, there are trends in composition that are noteworthy. Dwarf leaves contained on average less than $12 \%$ by weight carbon in the acid hydrolysed extract, whereas tall leaves have on average greater than $18 \%$ by weight carbon in this biochemical fraction (Tables 1 and 2). Moreover, dwarf leaves have a greater proportion of free lipids than tall leaves. The acid hydrolysable fraction of the fresh leaves contains the largest proportion of nitrogen and the major fraction of the nitrogen will most likely be in the form of proteins.

Preserved leaves. The compositions of the preserved leaves are presented in Table 3. The major biochemical group found in the leaves is the un-extractable compounds $(81.50 \%$ 'PL dwarf' and $73.22 \%$ 'PL tall'). In preserved leaves the acid hydrolysable fraction is relatively lower in concentration than

Table 1 Dwarf red mangrove fresh leaves: Biochemical and isotopic characteristics of separated chemical fractions

\begin{tabular}{|c|c|c|c|c|c|c|}
\hline \multirow[b]{2}{*}{ Leaf fraction } & \multirow[b]{2}{*}{ Parameter } & \multicolumn{3}{|c|}{ Leaf samples } & \multirow[b]{2}{*}{ Mean } & \multirow[b]{2}{*}{ St dev } \\
\hline & & D1 & D2 & D3 & & \\
\hline \multirow[t]{5}{*}{ Bulk leaf } & $\delta^{13} \mathrm{C}(\%)$ & -24.82 & -24.21 & -24.84 & -24.62 & 0.36 \\
\hline & $\delta^{15} \mathrm{~N}(\%)$ & -12.14 & -11.35 & -6.47 & -9.99 & 3.07 \\
\hline & TOC (\%) & 51.57 & 43.89 & 50.35 & 48.60 & 4.13 \\
\hline & $\mathrm{TN}(\%)$ & 1.12 & 1.15 & 1.11 & 1.13 & 0.02 \\
\hline & $\mathrm{C} / \mathrm{N}$ & 53.72 & 44.73 & 52.94 & 50.46 & 4.98 \\
\hline \multirow[t]{3}{*}{ Lipids } & $\begin{array}{l}\text { Composition } \\
(\%)\end{array}$ & 9.42 & 5.80 & 7.23 & 7.49 & 1.83 \\
\hline & $\delta^{13} \mathrm{C}(\%)$ & -27.06 & -27.67 & -29.15 & -27.96 & 1.07 \\
\hline & TOC $(\%)$ & 42.68 & 61.81 & 66.83 & 57.11 & 12.75 \\
\hline \multirow[t]{6}{*}{ Acid hydrolysate } & $\begin{array}{l}\text { Composition } \\
(\%)\end{array}$ & 4.25 & 5.74 & 3.78 & 4.59 & 1.02 \\
\hline & $\delta^{13} \mathrm{C}(\%)$ & -22.97 & -23.10 & -23.47 & -23.18 & 0.26 \\
\hline & $\delta^{15} \mathrm{~N}(\%)$ & -11.87 & -11.83 & -2.65 & -8.78 & 5.31 \\
\hline & TOC $(\%)$ & 27.68 & 25.97 & 24.55 & 26.07 & 1.57 \\
\hline & $\mathrm{TN}(\%)$ & 2.92 & 2.42 & 2.18 & 2.51 & 0.38 \\
\hline & $\mathrm{C} / \mathrm{N}$ & 11.06 & 12.52 & 13.14 & 12.24 & 1.07 \\
\hline \multirow[t]{3}{*}{ Water soluble } & $\begin{array}{l}\text { Composition } \\
(\%)\end{array}$ & 5.24 & 19.59 & 20.51 & 15.11 & 8.56 \\
\hline & $\delta^{13} \mathrm{C}(\%)$ & -25.34 & -25.24 & -26.11 & -25.56 & 0.48 \\
\hline & TOC $(\%)$ & 31.09 & 26.63 & 31.52 & 29.75 & 2.71 \\
\hline \multirow[t]{3}{*}{ Remainder } & $\begin{array}{l}\text { Composition } \\
(\%)\end{array}$ & 81.08 & 68.87 & 68.48 & 72.81 & 7.16 \\
\hline & $\delta^{13} \mathrm{C}(\%)$ & -24.55 & -24.78 & -24.67 & -24.67 & 0.12 \\
\hline & TOC (\%) & 59.91 & 54.62 & 59.77 & 58.10 & 3.01 \\
\hline
\end{tabular}

Table 2 Tall red mangrove fresh leaves: Biochemical and isotopic characteristics of separated chemical fractions

\begin{tabular}{|c|c|c|c|c|c|c|}
\hline \multirow[b]{2}{*}{ Leaf fraction } & \multirow[b]{2}{*}{ Parameter } & \multicolumn{3}{|c|}{ Leaf samples } & \multirow[b]{2}{*}{ Mean } & \multirow[b]{2}{*}{ St dev } \\
\hline & & $\mathrm{T} 1$ & $\mathrm{~T} 2$ & $\mathrm{~T} 3$ & & \\
\hline \multirow[t]{5}{*}{ Bulk leaf } & $\delta^{13} \mathrm{C}(\%)$ & -28.72 & -29.52 & -26.54 & -28.26 & 1.54 \\
\hline & $\delta^{15} \mathrm{~N}(\% 0)$ & -0.73 & 0.45 & 0.48 & 0.07 & 0.69 \\
\hline & TOC $(\%)$ & 47.64 & 46.59 & 47.32 & 47.18 & 0.54 \\
\hline & $\mathrm{TN}(\%)$ & 0.92 & 1.04 & 1.28 & 1.08 & 0.19 \\
\hline & $\mathrm{C} / \mathrm{N}$ & 61.46 & 52.94 & 43.13 & 52.51 & 9.17 \\
\hline \multirow[t]{3}{*}{ Lipids } & $\begin{array}{c}\text { Composition } \\
(\%)\end{array}$ & 6.04 & 5.14 & 6.35 & 5.84 & 0.63 \\
\hline & $\delta^{13} \mathrm{C}(\%)$ & -29.09 & -32.11 & -29.80 & -30.33 & 1.58 \\
\hline & TOC $(\%)$ & 58.24 & 65.60 & 59.16 & 61.00 & 4.01 \\
\hline \multirow[t]{6}{*}{$\begin{array}{l}\text { Acid } \\
\text { hydrolysate }\end{array}$} & $\begin{array}{l}\text { Composition } \\
(\%)\end{array}$ & 4.80 & 7.16 & 9.29 & 7.08 & 2.25 \\
\hline & $\delta^{13} \mathrm{C}(\%)$ & -26.39 & -26.39 & -25.00 & -25.93 & 0.80 \\
\hline & $\delta^{15} \mathrm{~N}(\% 0)$ & 1.22 & 0.02 & 0.96 & 0.73 & 0.63 \\
\hline & TOC $(\%)$ & 25.85 & 21.91 & 24.00 & 23.92 & 1.97 \\
\hline & TN $(\%)$ & 2.42 & 2.02 & 2.74 & 2.39 & 0.36 \\
\hline & $\mathrm{C} / \mathrm{N}$ & 12.46 & 12.65 & 10.22 & 11.78 & 1.35 \\
\hline \multirow[t]{3}{*}{ Water soluble } & $\begin{array}{l}\text { Composition } \\
(\%)\end{array}$ & 18.81 & 14.94 & 22.22 & 18.66 & 3.64 \\
\hline & $\delta^{13} \mathrm{C}(\%)$ & -29.01 & -29.04 & -27.49 & -28.51 & 0.89 \\
\hline & TOC $(\%)$ & 27.85 & 32.95 & 31.38 & 30.73 & 2.61 \\
\hline \multirow[t]{3}{*}{ Remainder } & $\begin{array}{l}\text { Composition } \\
(\%)\end{array}$ & 70.35 & 72.76 & 62.14 & 68.41 & 5.57 \\
\hline & $\delta^{13} \mathrm{C}(\%)$ & -28.10 & -28.77 & -27.03 & -27.97 & 0.88 \\
\hline & TOC $(\%)$ & 58.77 & 60.44 & 58.58 & 59.26 & 1.02 \\
\hline
\end{tabular}

in their fresh counterparts $(2.92 \%$ 'PL dwarf' and $2.50 \%$ 'PL tall' $v$ s. mean $=4.59 \%$ (fresh dwarf; $n=3$ ) and mean $=7.08 \%$ (fresh tall; $n=3$ )). Lipids, on the other hand, are relatively less concentrated in 'PL dwarf' $(2.47 \%)$ as compared to 'PL tall' $(6.88 \%)$, dwarf $($ mean $=7.49 \% ; n=3)$ and tall $(5.85 \% ; n=3)$ fresh leaves (Tables 1, 2 and 3). The water-soluble fraction is similar in preserved leaves and fresh leaves (Table 3). TOC and $\mathrm{C} / \mathrm{N}$ are lower in preserved leaves when compared to fresh leaves both in the bulk leaf and in the bound amino acid fraction (Tables 1, 2 and 3). In contrast to the fresh leaves, the

Table 3 Preserved leaves: Biochemical and isotopic characteristics of separated chemical fractions

\begin{tabular}{|c|c|c|c|}
\hline \multirow[b]{2}{*}{ Leaf fraction } & \multirow[b]{2}{*}{ Parameter } & \multicolumn{2}{|c|}{ Sample codes } \\
\hline & & 'PL dwarf' & 'PL tall' \\
\hline \multirow[t]{5}{*}{ Bulk leaf } & $\delta^{13} \mathrm{C}(\%)$ & -26.03 & -27.11 \\
\hline & $\delta^{15} \mathrm{~N}(\% 0)$ & -2.25 & -2.42 \\
\hline & TOC $(\%)$ & 44.08 & 44.81 \\
\hline & TN $(\%)$ & 0.94 & 1.14 \\
\hline & $\mathrm{C} / \mathrm{N}$ & 47.20 & 39.44 \\
\hline \multirow{3}{*}{ Lipids } & Composition $(\%)$ & 2.47 & 6.88 \\
\hline & $\delta^{13} \mathrm{C}(\%)$ & -26.25 & -27.25 \\
\hline & TOC $(\%)$ & 40.09 & 42.36 \\
\hline \multirow[t]{6}{*}{ Acid hydrolysate } & Composition $(\%)$ & 2.92 & 2.50 \\
\hline & $\delta^{13} \mathrm{C}(\%)$ & -22.58 & -24.59 \\
\hline & $\delta^{15} \mathrm{~N}(\% 0)$ & -0.46 & -0.60 \\
\hline & TOC $(\%)$ & 19.00 & 23.90 \\
\hline & TN $(\%)$ & 3.76 & 5.53 \\
\hline & $\mathrm{C} / \mathrm{N}$ & 5.90 & 5.04 \\
\hline \multirow{6}{*}{ Water soluble } & Composition $(\%)$ & 13.10 & 17.39 \\
\hline & $\delta^{13} \mathrm{C}(\% \circ)$ & -24.77 & -26.38 \\
\hline & $\delta^{15} \mathrm{~N}(\% 0)$ & -4.94 & -4.69 \\
\hline & TOC $(\%)$ & 13.57 & 13.12 \\
\hline & $\mathrm{TN}(\%)$ & 0.45 & 0.46 \\
\hline & $\mathrm{C} / \mathrm{N}$ & 29.83 & 28.41 \\
\hline \multirow[t]{6}{*}{ Remainder } & Composition $(\%)$ & 81.50 & 73.22 \\
\hline & $\delta^{13} \mathrm{C}(\%)$ & -27.63 & -29.53 \\
\hline & $\delta^{15} \mathrm{~N}(\% 0)$ & -14.61 & 0.57 \\
\hline & TOC $(\%)$ & 57.4 & N.A. \\
\hline & TN $(\%)$ & 0.86 & N.A. \\
\hline & $\mathrm{C} / \mathrm{N}$ & 67.13 & N.A. \\
\hline
\end{tabular}


preserved leaves contain nitrogen in the water-soluble fraction ('PL dwarf', $0.45 \%$; 'PL tall', $0.46 \%$ ) and the residual, unextractable fraction ('PL dwarf', $0.86 \%$; 'PL tall' concentration is not available).

\section{Carbon and nitrogen isotopic composition of chemical fractions in red mangrove leaves}

Fresh leaves. The carbon and nitrogen isotopic composition of each chemically extracted compound group for dwarf and tall leaves are shown in Tables 1 and 2. Each compound group is isotopically distinct from the bulk leaf, but without exception each has isotopic signatures $\left(\delta^{13} \mathrm{C}\right.$ and $\left.\delta^{15} \mathrm{~N}\right)$ indicative of the parent leaf (Tables 1 and 2). The mean $\delta^{13} \mathrm{C}$ composition of free lipids is $\sim 2.5 \%$ more positive in leaves from dwarf trees compared with those from tall trees $(n=3)$. In contrast to the lipids the carbon isotopic composition of the acid hydrolysable fraction (bound amino acids) in all fresh leaves is $\sim 2 \%$ heavier than the corresponding parent leaf (Tables 1 and 2). The remainder of the leaf, which does not contain a measurable amount of nitrogen, follows a similar trend with respect to the $\delta^{13} \mathrm{C}$ composition, being $\sim 2.5 \%$ o heavier in leaves from dwarf trees compared with those from tall trees. The only measurable nitrogen-containing fraction of the leaf is that within the bound amino acids. The carbon isotopic signature follows the same trend as above $(\sim 2.5 \%$ more positive in leaves from dwarf trees compared with those from tall trees). The nitrogen isotopic compositions are also indicative of the parent leaves being $\sim 9.5 \%$ o lighter in the leaves from dwarf trees compared with those from tall trees (Tables 1 and 2).

Preserved leaves. A $1-2 \%$ difference between the $\delta^{13} \mathrm{C}$ values was evident between the two leaves in each biochemical fraction, in a consistent direction (dwarf $>$ tall). $\delta^{15} \mathrm{~N}$ values were similar in both of the preserved leaves in each fraction of biochemicals and were distinctly different in leaves from dwarf trees compared with those from tall trees (Tables 1-3). The water-soluble fraction (Table 3), in contrast to the fresh leaves, contained nitrogen and each leaf had a similar nitrogen isotopic composition ( -4.94 and $-4.69 \%$ for 'PL dwarf' and 'PL tall', respectively; Table 3). The lipid fractions of each dwarf and tall red mangrove leaf analyzed as part of this study are relatively light $(\sim 3 \%)$ in carbon isotopic composition compared with the parent (bulk) leaf (Tables 1 and 2). The $\delta^{13} \mathrm{C}$ values of the residual leaf fractions of 'PL dwarf' and 'PL tall' were heavier by $\sim 1.5 \%$ o than $\delta^{13} \mathrm{C}$ values for bulk 'PL dwarf' and 'PL tall'. $\delta^{15} \mathrm{~N}$ values of the residual biochemical fraction were distinctive for each preserved leaf. 'PL dwarf' had a $\delta^{15} \mathrm{~N}$ value similar to that of fresh leaves from dwarf red mangrove (-14.61\% vs. $-9.99 \%$; Tables 1 and 3$)$ whereas 'PL tall' had a $\delta^{15} \mathrm{~N}$ value similar to that of fresh leaves from tall red mangrove (0.57 vs. $0.07 \%$, Tables 2 and 3$)$.

\section{Distributions of individual amino acids in red mangrove leaves}

Fresh leaves. Leaves from tall trees contain a greater absolute abundance of amino acids than dwarf leaves (Fig. 1a).

However, the relative abundance of identifiable individual amino acids within the leaves from dwarf and tall trees is similar (Fig. 1a). The only noticeable difference between leaves from dwarf and tall trees is observed with the largest amino acid component, which is alanine in the tall leaves, whereas in the dwarf leaves it is glutamic acid. However, the two groups of leaves cannot be statistically distinguished on the basis of their amino acid composition ( $T<T_{\text {crit }}$ at $\left.\alpha=0.05\right)$.

Preserved leaves. Preserved leaves are depleted in their absolute abundance of amino acids when compared to the fresh leaves (Fig. 1b) and the composition of amino acids is also clearly different. Glycine, tyrosine and arginine are all undetectable in the preserved leaf and ten of the twelve remaining amino acids are present at a lower relative concentration to those in the fresh leaves. Proline and hydroxy-proline are the only amino acids that are present at concentrations within one standard deviation of the modern leaves (proline 4.69, 3.95 vs. 3.34, $5.60 \mathrm{ng} \mathrm{mg}^{-1}$; 'PL dwarf', 'PL tall' vs. fresh dwarf, tall, respectively), or greater (hydroxyproline $2.12,1.98$ vs. $0.49,1.23 \mathrm{ng} \mathrm{mg}^{-1}$; 'PL dwarf', 'PL tall' vs. fresh dwarf, tall, respectively) quantities in the preserved leaves versus the fresh leaves (Fig. 1b).

Compound specific carbon and nitrogen isotopic composition of amino acids in red mangrove leaves

Fresh leaves. The compound specific carbon isotopic compositions of individual amino acids in leaves from dwarf and tall trees show a wide range of $\delta^{13} \mathrm{C}$ values $(-37.17 \%$ o to $-2.13 \%$; Table 4$)$. The most negative $\delta^{13} \mathrm{C}$ amino acid for leaves from dwarf and tall trees is leucine $(-37.17 \%$, $-34.78 \%$, respectively), the most positive is threonine $(-2.13 \%,-4.49 \%$, respectively). Fig. 2a shows the average difference between the carbon isotopic composition $\left(\Delta \delta^{13} \mathrm{C}\right)$ of the amino acids for the three leaves from dwarf and tall trees analyzed (dwarf-tall (or tall-dwarf); range bars represent biosynthetic variance (the actual isotopic numbers observed for each leaf analyzed) within each group of three leaves. The range of $\delta^{13} \mathrm{C}$ within the dwarf and within the tall leaf groupings is clearly large (Table 4). However, the $\delta^{13} \mathrm{C}$ signature for seven of the twelve amino acids is significantly different between dwarf versus tall leaves

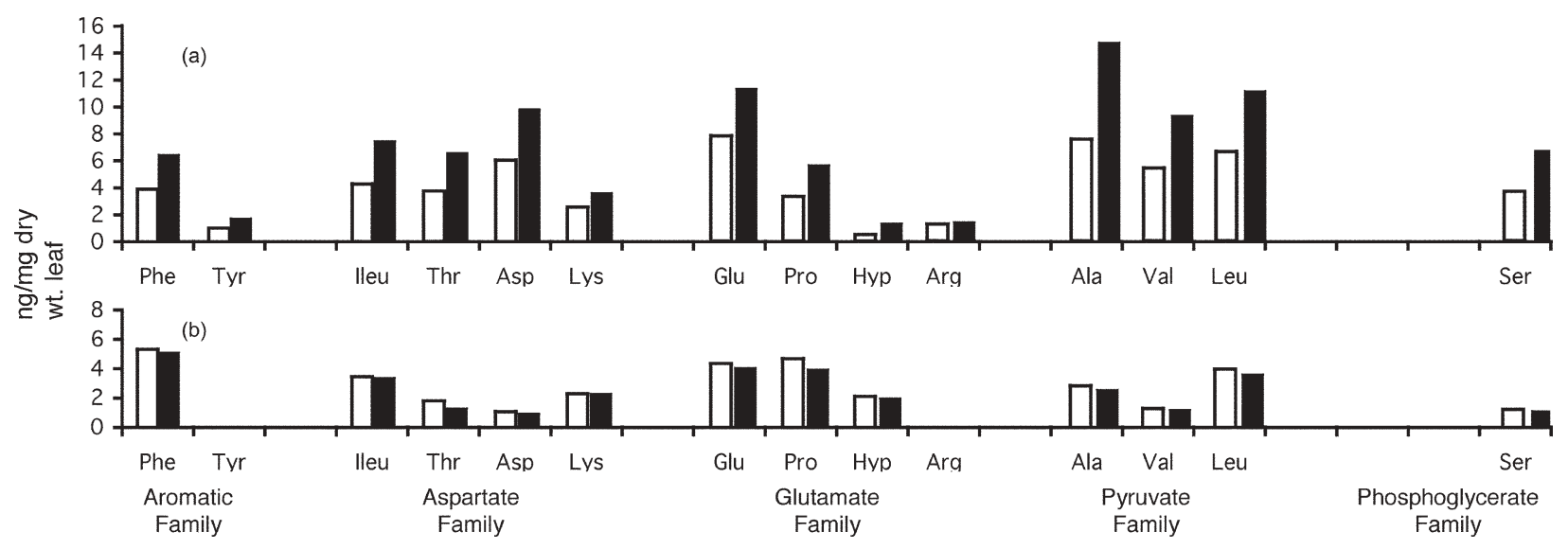

Fig. 1 Distribution of bound amino acids (ng mg ${ }^{-1}$ dry wt. leaf) in: (a) Fresh leaves from dwarf (open bars; $n=3$ ) and tall (solid bars; $n=3$ ) Red mangrove. (b) Preserved leaves 1 (open bars; $n=1$ ) and 2 (solid bars; $n=1$ ). 
Table $4 \delta^{13} \mathrm{C}$ values for individual amino acids in fresh dwarf and tall red mangrove leaves

\begin{tabular}{|c|c|c|c|c|c|c|c|c|c|c|}
\hline \multirow[b]{2}{*}{ Amino acid } & \multicolumn{5}{|c|}{ Dwarf red mangrove leaves } & \multicolumn{5}{|c|}{ Tall red mangrove leaves } \\
\hline & D1 & $\mathrm{D} 2$ & D3 & Mean & Variance & $\mathrm{T} 1$ & $\mathrm{~T} 2$ & $\mathrm{~T} 3$ & Mean & Variance \\
\hline Phenylalanine & -23.46 & -23.38 & -22.91 & -23.25 & 0.30 & -25.90 & -27.58 & -25.42 & -26.30 & 1.13 \\
\hline Tyrosine & -23.41 & -22.13 & & -22.77 & 0.91 & -24.60 & -25.30 & -22.41 & -24.10 & 1.51 \\
\hline Iso-leucine & -24.15 & -19.78 & -19.63 & -21.19 & 2.57 & -28.89 & -27.21 & -22.86 & -26.32 & 3.11 \\
\hline Threonine & -10.24 & -4.49 & -5.61 & -6.78 & 3.05 & -2.13 & -3.31 & -7.61 & -4.35 & 2.88 \\
\hline Aspartic acid & -22.39 & -20.82 & -23.73 & -22.31 & 1.46 & -27.44 & -25.42 & -21.51 & -24.79 & 3.01 \\
\hline Lysine & -22.80 & -20.51 & -22.79 & -22.03 & 1.32 & -26.06 & -25.83 & -23.30 & -25.06 & 1.53 \\
\hline Glutamic acid & -22.68 & -20.26 & -21.24 & -21.39 & 1.22 & -31.03 & -24.17 & -21.86 & -25.69 & 4.77 \\
\hline Proline & -21.00 & -19.01 & -21.49 & -20.50 & 1.31 & -24.29 & -24.55 & -22.61 & -23.82 & 1.05 \\
\hline Alanine & -17.56 & -21.18 & -18.76 & -19.17 & 1.84 & -20.32 & -22.21 & -22.06 & -21.53 & 1.05 \\
\hline Valine & -25.45 & -25.20 & -24.66 & -25.10 & 0.40 & -25.75 & -29.81 & -26.81 & -27.46 & 2.11 \\
\hline Leucine & -34.78 & -31.89 & -33.26 & -33.31 & 1.45 & -34.42 & -37.17 & -33.65 & -35.08 & 1.85 \\
\hline Serine & -13.98 & -14.23 & -15.28 & -14.50 & 0.69 & -20.37 & -19.72 & -16.28 & -18.79 & 2.20 \\
\hline
\end{tabular}

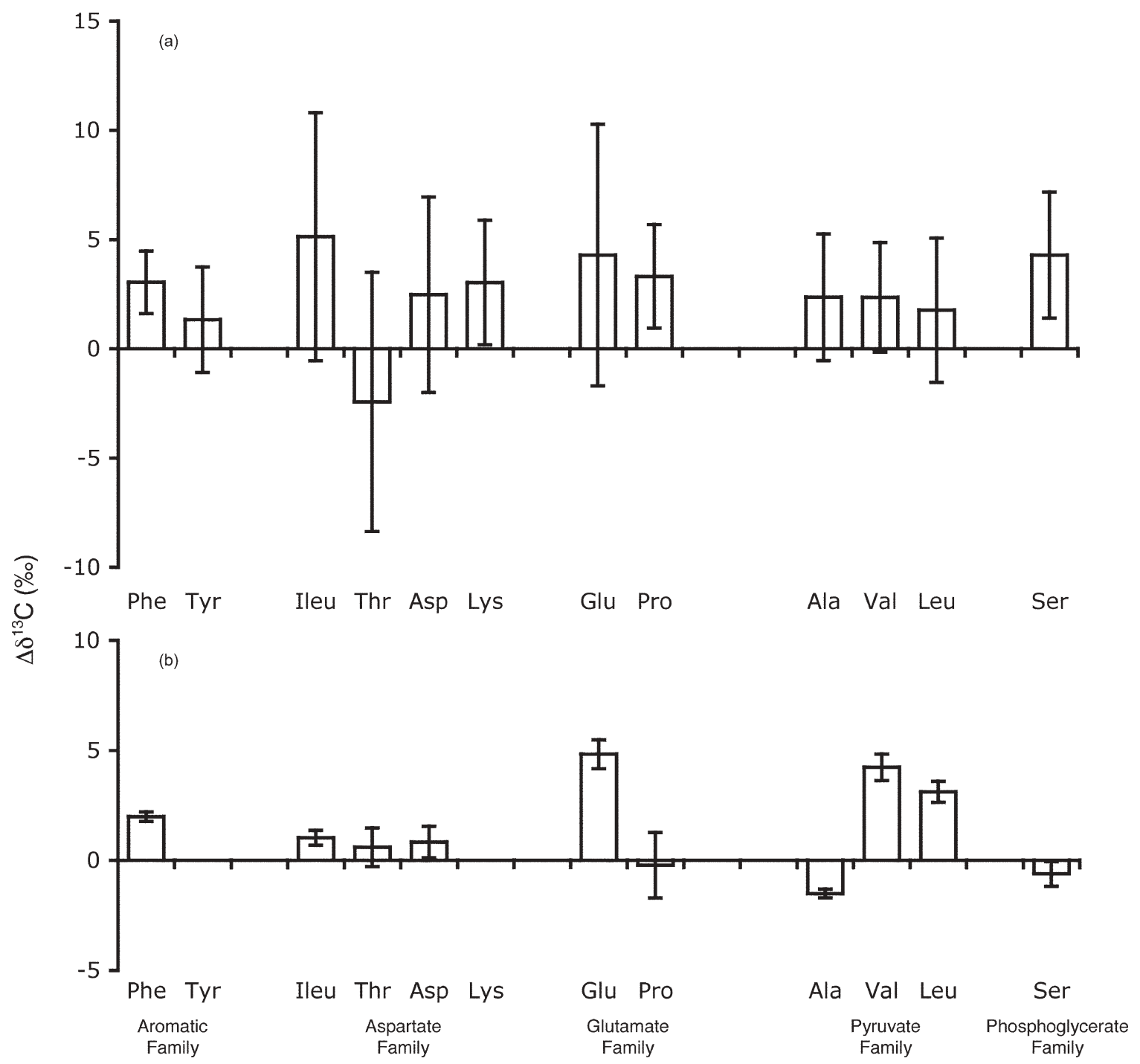

Fig. 2 (a) The difference between the carbon isotopic composition $\left(\Delta \delta^{\mathbf{1 3}} \mathrm{C}\right)$ of bound amino acids in fresh leaves from dwarf and tall Red mangrove, range bars are representative biosynthetic variation between the three leaves from each red mangrove stand. (b) The difference between the carbon isotopic composition $\left(\Delta \delta^{\mathbf{1 3}} \mathrm{C}\right)$ of bound amino acids in 'PL dwarf' $(n=3)$ and 'PL tall' $(n=3)$, error bars are representative of \pm one standard deviation from the mean. Key: alanine (ala), threonine (thr), serine (ser), valine (val), iso-leucine (ileu), hydroxy-proline (hyp), proline (pro), aspartic acid (asp), glutamic acid (glu), phenylalanine (phe), lysine (lys), tyrocine (tyr).

( $T<T_{\text {crit }}$ at $\alpha=0.05$; alanine, threonine, serine, valine, proline, aspartic acid and glutamic acid). Dwarf and tall leaves could not be distinguished on the basis of $\delta^{13} \mathrm{C}$ values from the analyses of leucine, iso-leucine, phenylalanine and tyrosine. Of the seven amino acids that can be used to distinguish between dwarf and tall trees, six have significantly $\left(T<T_{\text {crit }}\right.$ at $\alpha=$
$0.05)$ more negative isotopic compositions (mean $=\sim 3 \%$; Fig. 2; Table 4) in leaves from tall trees versus those from dwarf trees. The one exception to this is threonine, in that the $\delta^{\mathbf{1 3}} \mathrm{C}$ values of this compound in the dwarf leaves is, on average, $2.56 \%$ more negative than that in tall leaves.

The stable nitrogen isotopic composition of the amino acids 


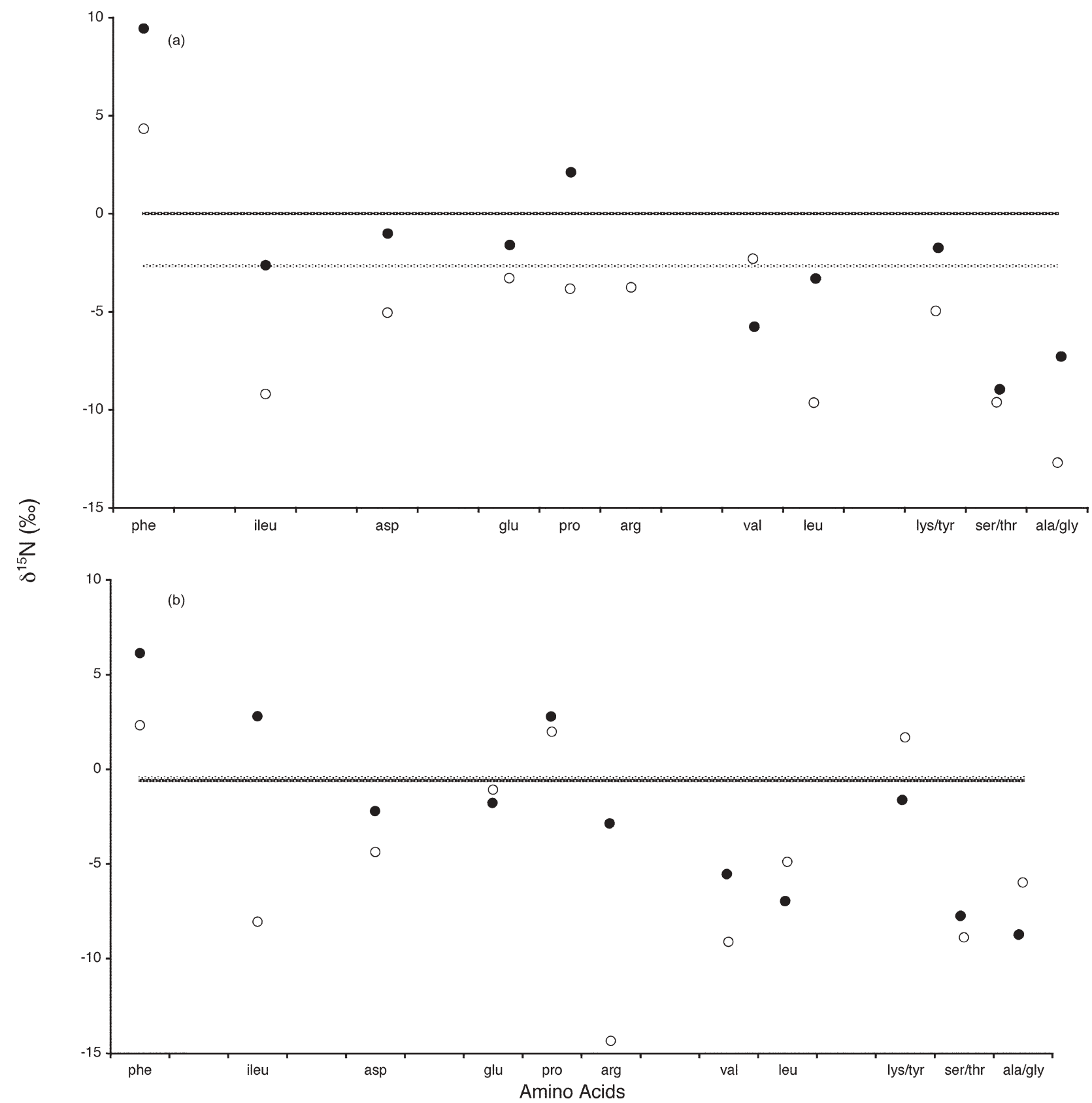

Fig. 3 (a) Compound specific isotopic analysis $\left(\delta^{15} \mathrm{~N}\right)$ of bound amino acids in fresh dwarf Red mangrove (open circles; $\left.n=1\right)$ and fresh tall Red mangrove (solid dots; $n=1$ ) leaves. The lines represent the $\delta^{15} \mathrm{~N}$ of the bound hydrolysate fraction extracted from dwarf red mangrove (light gray line) and tall red mangrove (dark gray line) leaves. (b) Compound specific isotopic analysis $\left(\delta^{15} \mathrm{~N}\right)$ of bound amino acids in 'PL dwarf' (open circles; $n=1$ ) and 'PL tall' (solid dots; $n=1$ ). The lines represent the $\delta^{15} \mathrm{~N}$ of the bound hydrolysate fraction extracted from 'PL dwarf' (light gray line) and 'PL tall' (dark gray line).

was analyzed on two leaf samples (one dwarf and one tall), along with the amino acid standard. The range of $\delta^{15} \mathrm{~N}$ values is from $-9.6 \%$ to $+9.5 \%$ (Fig. 3) with the isotopically lightest compounds being the co-eluting serine and threonine within the dwarf leaf $(-9.6 \%$ ) and the heaviest being phenylalanine $(+9.5 \%)$ in the tall leaf (Fig. 3a). All but one amino acid (valine) in the dwarf leaf has more negative $\delta^{15} \mathrm{~N}$ values than the tall leaf, with a difference of up to $\sim 6 \%$ (iso-leucine) (Fig. 3a).

Preserved leaves. $\delta^{13} \mathrm{C}$ values of individual amino acids in the preserved leaves ranged from $-30.55 \%$ (leucine) to $+1.44 \%$ (threonine; Table 5). The most negative $\delta^{13} \mathrm{C}$ amino acid in 'PL dwarf' and 'PL tall' is leucine $(-27.43 \%$, $-30.55 \%$, respectively) the most positive is threonine $(+1.44 \% 0,+0.84 \%$, respectively). When comparing average $\delta^{13} \mathrm{C}$ values of amino acids in fresh dwarf and tall leaves to average $\delta^{13} \mathrm{C}$ values of amino acids in preserved leaves, the preserved leaf amino acid compositions are significantly heavier $\left(T<T_{\text {crit }}\right.$ at $\alpha=0.05$; Table 5). $\Delta \delta^{13} \mathrm{C}$ between the two preserved leaves are shown in Fig. 2b. Seven of the ten detectable amino acids in 'PL dwarf' are heavier than 'PL tall', but these differences are within one standard deviation of the modern leaves (Fig. 2b). $\delta^{15} \mathrm{~N}$ values range from $-14.33 \%$ ( $\mathrm{arg}$, 'PL dwarf') to $+6.14 \%$ (phenylalanine; 'PL tall'). Six of the eight fully resolved amino acids were lighter in 'PL dwarf' versus 'PL tall' by from $-1.17 \%$ (proline) to $-11.53 \%$ o $(\arg )$. Glutamic acid and leucine were lighter in 'PL tall' ( +0.67 and $+1.99 \%$, respectively; Fig. $3 b)$.

\section{Discussion}

\section{Fresh dwarf and tall red mangrove leaves}

Biochemical fractions. The similarity in distribution of the majority of biochemical fractions in dwarf and tall red mangrove trees suggests that each of the stands has similar 
Table $5 \quad \delta^{13} \mathrm{C}$ values for individual amino acids in preserved leaves below dwarf and tall red mangrove stands $(n=3)$

\begin{tabular}{lrllll}
\hline & \multicolumn{2}{l}{ 'PL dwarf' } & & \multicolumn{2}{c}{ 'PL tall' } \\
\cline { 2 - 3 } \cline { 5 - 6 } Amino acid & Mean & Std dev & & Mean & \multirow{2}{*}{ Std dev } \\
\hline Phenylalanine & -23.27 & 0.08 & & -25.26 & 0.13 \\
Tyrosine & -15.73 & & & & \\
Iso-leucine & -18.46 & 0.11 & & -19.49 & 0.23 \\
Threonine & 1.44 & 0.79 & & 0.84 & 0.08 \\
Aspartic acid & -16.37 & 0.70 & & -17.21 & 0.01 \\
Lysine & -5.36 & & & \\
Glutamic acid & -18.74 & 0.46 & & -23.56 & 0.20 \\
Proline & -17.54 & 0.66 & & -17.32 & 0.83 \\
Alanine & -18.04 & 0.06 & & -16.53 & 0.13 \\
Valine & -22.43 & 0.16 & & -26.66 & 0.44 \\
Leucine & -27.43 & 0.13 & -30.55 & 0.34 \\
Serine & -3.24 & 0.25 & -2.63 & 0.30 \\
\hline
\end{tabular}

requirements for growth, and each are utilizing the available nutrients in a similar manner. The only exception is the relative depletion of bound amino acids in dwarf versus tall leaves. Amino acid synthesis requires relatively more phosphate molecules than lipid synthesis, ${ }^{21}$ and this could explain why the phosphate-limited (i.e. stressed) dwarf trees have a smaller proportion of bound amino acids within their leaves.

Although the stable carbon isotopic composition of each biochemical fraction in the fresh leaves are different compared to that of the bulk leaf, the tall and dwarf leaves can be distinguished on this basis. Tall leaves have a stable carbon isotopic composition that is $\sim 3 \%$ lighter than dwarf leaves for each biochemical fraction. Free lipids synthesis preferentially utilizes ${ }^{12} \mathrm{C}$ over ${ }^{13} \mathrm{C},{ }^{22-24}$ whereas amino acid synthesis retains ${ }^{13} \mathrm{C}$ and has a relatively heavy stable isotopic composition relative to the bulk leaf.

The unextractable leaf fraction does not contain nitrogen in any of the fresh leaves, and we assume that this fraction consists largely of tannins and lignins. Total polyphenolic compounds, including condensed tannins and residual phenolics (e.g., lignin) have been reported to comprise over $40 \%$ by weight of red mangrove leaves (using previously described methods, ${ }^{25}$ dwarf leaf $=41.7 \%$, tall leaf $=43.3 \%{ }^{26}$ ) with condensed tannins significantly more abundant in tall red mangrove leaves $(20.4 \%)$ than dwarf red mangrove leaves $(17.7 \%) .{ }^{26}$ There was no significant difference in percentage of the leaf remains after all extractions, between dwarf and tall red mangrove leaves analyzed in this study.

In summary, the carbon isotopic signature of the whole leaf, free lipids, water-soluble extract, and the residual leaf can be used to distinguish dwarf and tall red mangrove leaves. In addition the nitrogen isotopic composition of the whole leaf and the acid hydrolysed fraction of the leaf could be used in a similar manner.

Individual amino acids. The distributions of individual amino acids in dwarf and tall red mangrove leaves were similar (Fig. 1a.), implying that phosphorous limitation, excess nitrogen, water and/or salinity stress experienced by the dwarf red mangrove stands does not alter amino acid biosynthesis and metabolism. The range of $\delta^{13} \mathrm{C}$ values for all amino acids is wide (Table 4) as recognized in other plants. ${ }^{27}$ There is however, a general trend of $\delta^{13} \mathrm{C}$ values; the majority of amino acids (7 of 12) from tall leaves are relatively depleted in ${ }^{13} \mathrm{C}$ compared with the dwarf leaves. We do not suggest that the analysis of one individual amino acid would distinguish dwarf and tall red mangrove stands. However, if the total data set of all amino acids is used, the carbon isotopic signature of the leaf is reflected and can be used to discern stand structure.

Our preliminary nitrogen isotopic data suggest that the isotopic composition of all but one amino acid (valine) reflects the nitrogen isotopic composition of the bulk leaves. Leaves from dwarf trees are isotopically lighter than compared to leaves from tall trees (Fig. 3). The distribution of amino acids within tall and dwarf trees is similar and the carbon and nitrogen isotopic composition of each leaf appear to have a similar fractionation during synthesis. This suggests that, whatever the physiological differences between the two stands of red mangrove trees, they are not detectable through differences in amino acid fractionation. Differences between carbon and nitrogen incorporation into the plants are the most important processes for isotopic fractionation of these two nutrients. This finding implies that stable carbon and nitrogen isotopes could be used to assess gradients of nutrient limitation in this complex ecosystem.

Red mangrove leaves preserved in peat. The bulk isotopic signatures of preserved leaves from the peat do not reflect the isotopic compositions of the leaves from the living trees above them. These differences may suggest that the leaves have been diagenetically transformed since deposition; that the isotopic composition of red mangrove at each of the sites has changed since the time of deposition; or that the preserved leaves were transported from a different stand structure prior to deposition. Wooller et al., ${ }^{10}$ ascertained that the $\delta^{13} \mathrm{C}$ of senescent leaves from dwarf and tall red mangrove from Twin Cays retained the isotopic signature of the fresh leaves, so it is assumed that the differences in TOC and $\delta^{13} \mathrm{C}$ of the lipids in preserved versus fresh leaves must have occurred after deposition to the peat sediments. We believe that diagenetic degradation has selectively degraded ${ }^{12} \mathrm{C}$ versus ${ }^{13} \mathrm{C}$ in the lipid fraction of the preserved leaves, which would then assume a more positive $\delta^{13} \mathrm{C}$ signature. The relative depletion in TOC within lipid fractions of the leaves could therefore be explained by sedimentary diagenesis.

The low C/N in 'PL dwarf' and 'PL tall' (5.04 and 5.90, respectively) is indicative of a microbial signature. ${ }^{9,10}$ A relative accumulation of $\mathrm{TN}$ would suggest that there has been little or no degradation of nitrogen containing compounds, or that during microbial re-working a different pool of nitrogen was incorporated into the acid hydrolysable fraction of the preserved leaf. Based on the $\mathrm{C} / \mathrm{N}$ of the acid hydrolysed extract and the CSIA of amino acids in the preserved leaves we suggest that the acid hydrolysable fraction of PL dwarf and PL tall is reflecting a microbial signature.

The residual, un-extractable fraction of the preserved leaves contains nitrogen. Moreover, the $\delta^{\mathbf{1 5}} \mathrm{N}$ of PL dwarf is very light $\left(-14.61 \%\right.$ ) whereas, the $\delta^{15} \mathrm{~N}$ value of PL tall is similar to that of the $\delta^{15} \mathrm{~N}$ of fresh tall leaves $(+0.57 \%)$. The matrix surrounding the preserved leaves showed little variation in $\delta^{15} \mathrm{~N}\left(-2 \%\right.$ to $\left.1.75 \%{ }^{10}\right)$, indeed the only source of nitrogen to the peat sediments that has been shown to have such a wide variation of $\delta^{15} \mathrm{~N}$ values is the difference between fresh red mangrove leaves (leaves from dwarf versus tall red mangrove stands; Tables 1 and $2^{7,10}$ ). Nitrogen immobilization is known to occur in mangrove peat sediments, where it has been reported that nitrogen-containing compounds become bound/ absorbed by tannins and are thus effectively un-digestible by bacteria. ${ }^{16}$ For preserved leaves to retain a $\delta^{15} \mathrm{~N}$ signature in the residual chemical fraction that is different by $\sim 15 \%$, immobilization of nitrogen probably occurs rapidly, does not discriminate between ${ }^{14} \mathrm{~N}$ and ${ }^{15} \mathrm{~N}$, and therefore, possibly reflects the $\delta^{15} \mathrm{~N}$ composition of the original nitrogen in the leaf. We conclude that the residual chemical fractions of 'PL dwarf' and 'PL tall' have $\delta^{15} \mathrm{~N}$ signatures that reflect fallen leaves from dwarf and tall mangrove stands, respectively, and that this is the fraction that holds the greatest promise for determining stand structure from isotopic patterns in mangrove peat cores.

Compound specific isotopic analysis of amino acids shows that (1) labeling of all amino acids in both carbon and nitrogen is derived from the original plant carbon and nitrogen, but (2) 

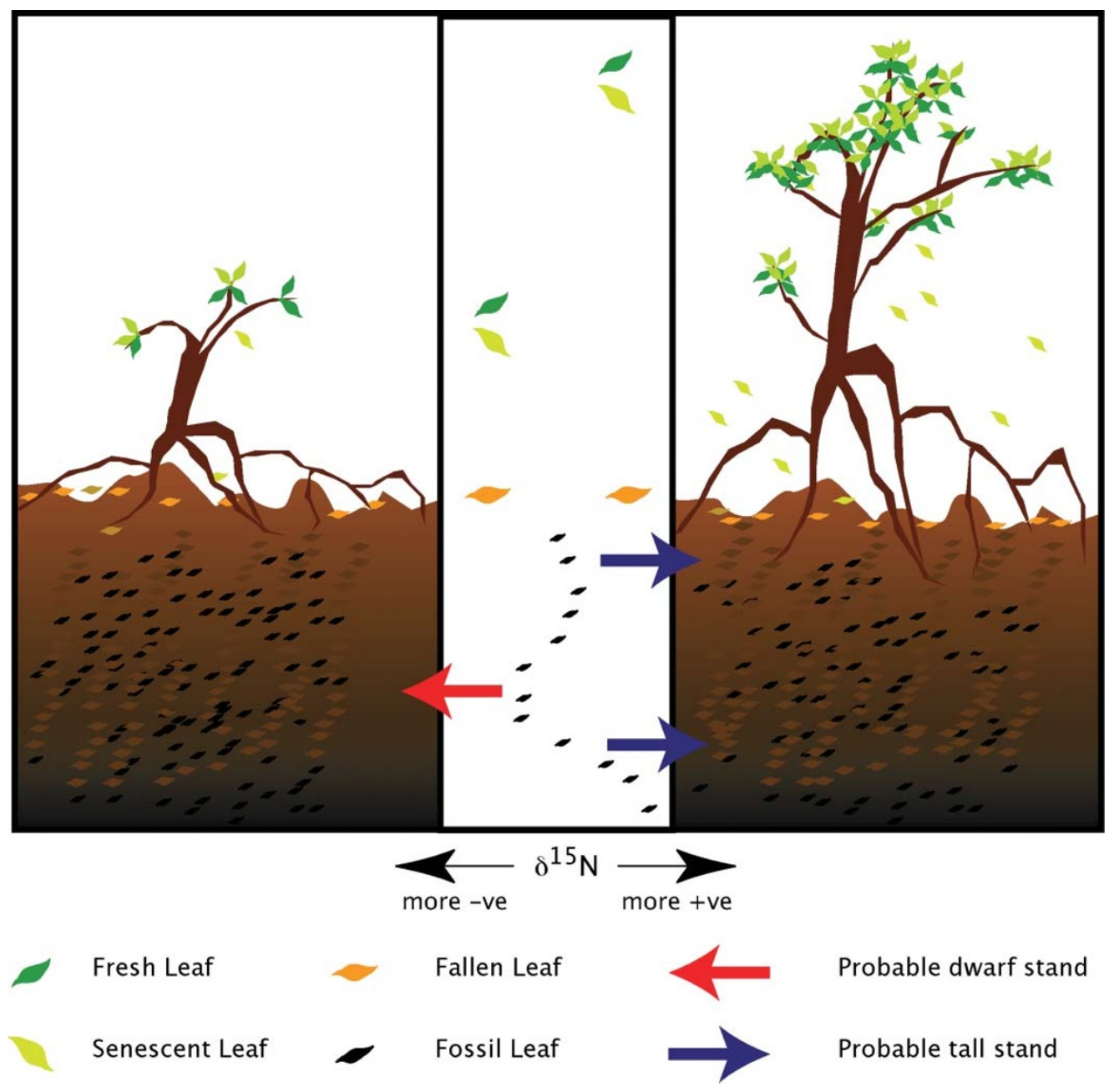

Fig. 4 Cartoon representation of how $\delta^{15} \mathrm{~N}$ values can be used to determine past mangrove stand structure.

microbes have completely altered the specific $\delta^{\mathbf{1 3}} \mathrm{C}$ values. Carbon isotopic differences from the source leaf are apparent. The nitrogen isotopic composition of individual amino acids in the preserved leaves, where differences between the same amino acid in the leaves are up to $10 \%$ (Fig. 3b), continue to hold the signature of modern dwarf verses tall red mangrove leaves.

Leaf fragments deposited below dwarf and tall red mangrove stands approximately 1000 years ago ${ }^{10}$ have been subjected to substantial degradation since initial deposition. Nevertheless, certain biochemical fractions still hold the original isotopic signatures. The $\delta^{15} \mathrm{~N}$ composition of the residual un-extractable fraction of two red mangrove leaves preserved in peat deposits at Twin Cays was nearly identical to the bulk $\delta^{15} \mathrm{~N}$ of fresh leaves collected at the same sites. The $\delta^{13} \mathrm{C}$ and $\delta^{15} \mathrm{~N}$ of amino acids were altered at the molecular level, but differences in the $\delta^{13} \mathrm{C}$ composition of the two leaves reflected the original source leaf (Fig. 4).

This research has shown how the stable isotopes of carbon and nitrogen might be used to predict past mangrove stand structure and alterations in nutrient limitation. The nature of the $\delta^{15} \mathrm{~N}$ of insoluble organic matter in preserved leaves holds promise and is the subject of our future work. Modern tree height gradients are indicative of nitrogen versus phosphorus limitation and height of the water table. Hence, the stable isotopes of carbon and nitrogen will be used to discern the response of red mangrove to environmental change.

\section{Acknowledgements}

We would like to thank the Station Managers, Dan Miller and Claudette DeCourley, for assistance at the Carrie Bow Marine
Station, Belize. This work was funded by NSF Biocomplexity awards to Myrna Jacobson and Marilyn Fogel (Grant numbers 99-81357 and 99-81535). With thanks to Diane O'Brien, Christian Ostertag-Henning, Maureen Reap and an anonymous reviewer whose constructive comments improved our paper.

\section{References}

1 A. M. Ellison and E. J. Farnsworth, Anthropogenic disturbance of Caribbean mangrove ecosystems: Past impacts, present trends, and future predictions, Biotropica, 1996, 28(4A), 549-565.

2 M. R. Murray, S. A. Zisman, P A. Furley, D. M. Munro, J. Gibson, J. Ratter, S. Bridgewater, C. A. Minty and C. J. Place, The mangroves of Belize Part 1. distribution, composition and classification, For. Ecol. Manage., 2003, 174(1-3), 265-279.

3 I. C. Feller, Effects of nutrient enrichment on growth and herbivory of dwarf red mangrove (Rhizophora mangle), Ecol. Monogr., 1995, 65(4), 477-505.

4 K. Kathiresan and B. L. Bingham, Biology of mangroves and mangrove ecosystems, Adv. Mar. Biol., 2001, 40, 81-251.

5 I. C. Feller, Nitrogen $v$ s. phosphorus limitation across an ecotonal gradient in a mangrove forest, in preparation.

6 I. C. Feller and K. L. McKee, Small gap creation in Belizean mangrove forests by a wood-boring insect, Biotropica, 1999, 31(4), 607-617.

7 K. L. McKee et al., Mangrove isotopic $\left(\delta^{15} \mathrm{~N}\right.$ and $\left.\delta^{\mathbf{1 3}} \mathrm{C}\right)$ fractionation across a nitrogen $v s$. phophorous limitation gradient, Ecology, 2002, 83(4), 1065-1075.

8 K. L. McKee, Mangrove species distribution and propagule predation in Belize: An exception to the dominance-predation hypothesis, Biotropica, 1995, 27(3), 334-345.

9 M. J. Wooller et al., Carbon and nitrogen stable isotopic variation in Laguncularia racemosa from Florida and Belize: Implications for trophic level studies, Hydrobiologia, 2003, 499(1), 13-23. 
10 M. J. Wooller et al., Towards a multi-proxy approach to mangrove palaeoecology: A taphonomic study of $\delta^{13} \mathrm{C}$ and $\delta^{15} \mathrm{~N}$ values in R. mangle leaves, Org. Geochem., 2003, 34(9), 1259-1276.

11 G. L. Cowie, J. I. Hedges and S. E. Calvert, Sources and relative reactivities of amino acids, neutral sugars, and lignin in an intermittently anoxic marine environment, Geochim. Cosmochim. Acta, 1992, 56, 1963-1978.

12 J. Haugen and R. Lichtentaler, Amino acid diagenesis, organic carbon and nitrogen mineralization in surface sediments from the inner Oslofjord, Norway, Geochim. Cosmochim. Acta, 1991, 55, 1649-1661.

13 S. M. Henrichs and J. W. Farrington, Early diagenesis of amino acids and organic matter in two coastal marine sediments, Geochim Cosmochim. Acta, 1987, 51, 1-15.

14 I. M. Horsfall and G. A. Wolff, Hydrolysable amino acids in sediments from the Porcupine Abyssal Plain, northeast Atlantic Ocean, Org. Geochem., 1997, 26(5/6), 311-320.

15 M. Terashima, Abundance of acidic amino acids and non-protein amino acids in carbonate and muddy sediments, and their relationship to diagenetic decomposition, Chem. Geol., 1991, 90, 123-131.

16 P. J. Hernes et al., Tannin diagenesis in mangrove leaves from a tropical estuary: A novel molecular approach, Geochim. Cosmochim. Acta, 2001, 65(18), 3109-3122.

17 D. M. O'Brien, M. L. Fogel and C. L. Boggs, Renewable and nonrenewable resources: Amino acid turnover and allocation to reproduction in Lepidoptera, Proc. Natl. Acad. Sci. USA, 2002, 99(7), 4413-4418

18 M. S. Fantle et al., A food web analysis of the juvenile blue crab, Callinectes sapidus, using stable isotopes in whole animals and individual amino acids, Oecologia, 1999, 120, 416-426.
19 M. J. Wooller, B. Collins and M. Fogel, The elemental analyzer sample carousel: loading an autosampler made easy, Rapid Commun. Mass Spectrom., 2001, 15, 1957-1959.

20 J. A. Silfer et al., Stable carbon isotope analysis of amino acid enantiomers by conventional isotope ratio mass spectrometry and combined gas-chromatography-isotope ratio mass spectrometry, Anal. Chem., 1991, 63, 370-374.

21 T. Paustian, Microbiology Webbed Out, University of Wisconsin-Madison, Madison, WI, 2003, http://www.bact.wisc. edu/microtextbook/.

22 M. J. DeNiro and S. Epstein, Mechanism of carbon isotope fractionation associated with the lipid synthesis, Science, 1977, 197, 261-263.

23 K. D. Monson and J. M. Hayes, Biosynthetic control of the natural abundance of carbon 13 at specific positions within fatty acids in Escherichia coli, J. Biol. Chem., 1980, 55, 11435-11441.

24 K. D. Monson and J. M. Hayes, Carbon isotopic fractionation in the biosynthesis of bacterial fatty acids. Ozonolysis of unsaturated fatty acids as a means of determining the intra-molecular distribution of carbon isotopes, Geochim. Cosmochim. Acta, 1982, 46, 139-149.

25 M. Price and L. Butler, Rapid visual estimation and spectrophotometric determination of tannin content of sorghym grain, J. Agric. Food Chem., 1977, 26, 1214-1218.

26 F. E. Kandil et al., Changes in proanthocyanidins, other flavonoids, and simple phenolics in Rhizophora mangle leaves during development and senescence, in preparation.

27 M. L. Fogel and N. Tuross, Transformation of plant biochemicals to geological macromolecules during early diagenesis, Oecologia, 1999, 120, 336-346. 